\title{
EXPERIMENTATION ON HEAT PIPE AND CFD ANALYSIS FOR PERFORMANCE ENHANCEMENT
}

\author{
Amod Dileep Khanvilkar', Shilpa Mondkar ${ }^{2}$, Sandeep M. Joshi ${ }^{3}$ \\ ${ }^{1}$ Student, Department of Mechanical Engineering, Pillai Institute of Information Technology, Navi Mumbai, \\ Maharashtra, India \\ ${ }^{2}$ Assistant Professor, Department of Mechanical Engineering, Pillai Institute of Information Technology, Navi \\ Mumbai, Maharashtra, India \\ ${ }^{3}$ Assistant Professor, Department of Mechanical Engineering, Pillai Institute of Information Technology, Navi \\ Mumbai, Maharashtra, India
}

\begin{abstract}
Heat Pipe is a heat transfer device used in many applications and it is very similar in some respects to the thermosyphon. Since there were several limitations of thermosyphon, heat pipe was developed. The idea of the heat pipe was first suggested in 1942, since then over a several decades the serious development of a heat pipe took place. Heat pipe mainly consists of three regions viz. evaporator, adiabatic and condenser section. The heat pipe differs from the thermosyphon by virtue of its ability to transport heat against gravity by an evaporation-condensation cycle. This research work includes experimentation on available heat pipe, development of CFD model and its validation with experimental results using CFD Tool. The results obtained by CFD are in good agreement with an experimental results. Since the heat pipe is used for transferring the heat, this research work focuses on increasing the heat transfer by modified model, modifications in terms of increased surface area, is proposed. From CFD analysis it was found that the proposed modified heat pipe shows enhancement in performance in terms of heat transfer rate by $19 \%$ when it is simulated for without heat sink case and $45 \%$ while with heat sink case, compared to conventional heat pipe. The mixture multiphase model from CFD too is used for simulation of heat pipe.
\end{abstract}

Keywords: Heat pipe, CFD, Multiphase

\section{INTRODUCTION}

Heat pipe is a device of very high effective thermal conductivity which varies with the length of heat pipe. The effective thermal conductivity of heat pipe can approach 100 $\mathrm{kW} /(\mathrm{m}-\mathrm{K})$ for long heat pipes, in comparison with approximately $0.4 \mathrm{~kW} /(\mathrm{m}-\mathrm{K})$ for copper $\operatorname{rod}[1]$. The heat pipe is similar in some respects to the thermosyphon, Fig.1.1. A small quantity of the water is placed in the sealed tube. The lower end of the tube is heated. The liquid vaporizes and the vapour moves to the cold end of thermosyphon where it is condensed. The condensate is returned along the length of wall to the hot end by means of gravity [1].

The heat pipe is constructed with a wick on inside of the pipe and the capillary forces return the condensate to evaporator. This is the only difference between thermosyphon and heat pipe, Fig. 1.2. Hence, the heat pipe can be used in any orientation. Heat pipe will give a better performance if evaporator is in lowest position because gravitational forces will assist the capillary forces [1].

At the hot interface of heat pipe a liquid in contact with a thermally conductive solid surface turns into the vapour by absorbing the heat from that surface. The vapour then travels along the heat pipe and condenses back into a liquid by releasing latent heat. The liquid then returns to the hot interface through capillary action, and the cycle repeats,

Fig.1.3. The effective thermal conductivity varies with the heat pipe length, and can reach 200 times in comparison with copper rod, as mentioned earlier.

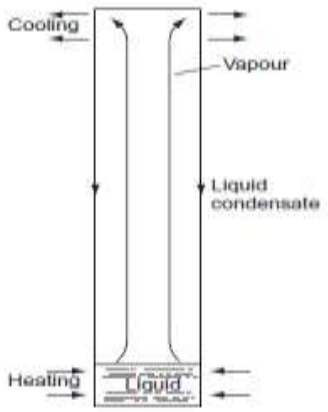

Fig-1.1:Thermosyphon [2]

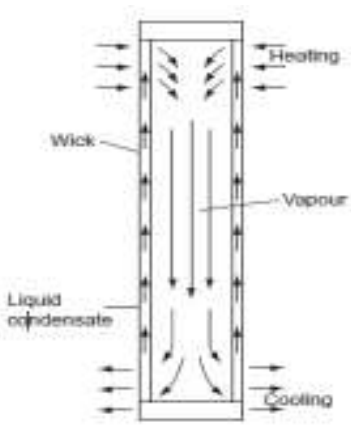

Fig-1.2:Heat Pipe [2]

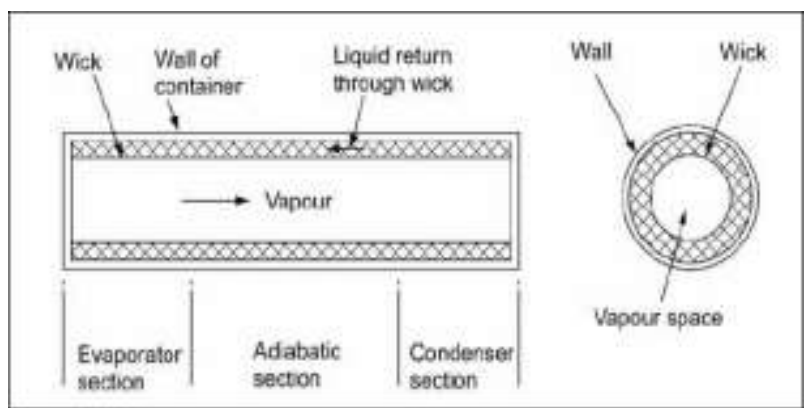

Fig-1.3: The main regions of heat pipe [2] 
Heat pipe are having both terrestrial and non- terrestrial applications. Heat pipes are used in energy storage systems, nuclear reactors, aircraft and space applications, renewable energy systems, prevention of permafrost, snow melting and deicing, heat pipes in food industries etc [2].

\section{METHODOLOGY}

This section discusses the methodology used for this project.

\subsection{Literature Study}

From the literature review it was concluded that various kind of work has been done on heat pipe since its patent in 1942. It was found that enhancing the performance of heat pipe has become necessary because of its wide applications. So, this has been scope of this project.

\subsection{Experiment on Heat Pipe}

The experiment was performed on the heat pipe to validate the CFD model.

\subsection{CFD Analysis of Heat Pipe}

Using the multiphase model CFD Analysis of Heat pipe and Proposed Heat pipe is performed.

\subsection{Results of CFD Analysis}

After pre-processing and solver the final stage is postprocessing which includes XY plots and generating reports of CFD analysis. The results obtained from CFD model are validated using an experimental results.

\subsection{Conclusion}

The results obtained from CFD for heat pipe and proposed heat pipe are compared and conclusion is presented.

\section{EXPERIMENT ON HEAT PIPE}

Experiment performed on heat pipe is discussed in the following section.

\subsection{Aim}

The aim of experiment is to validate the results obtained from CFD.

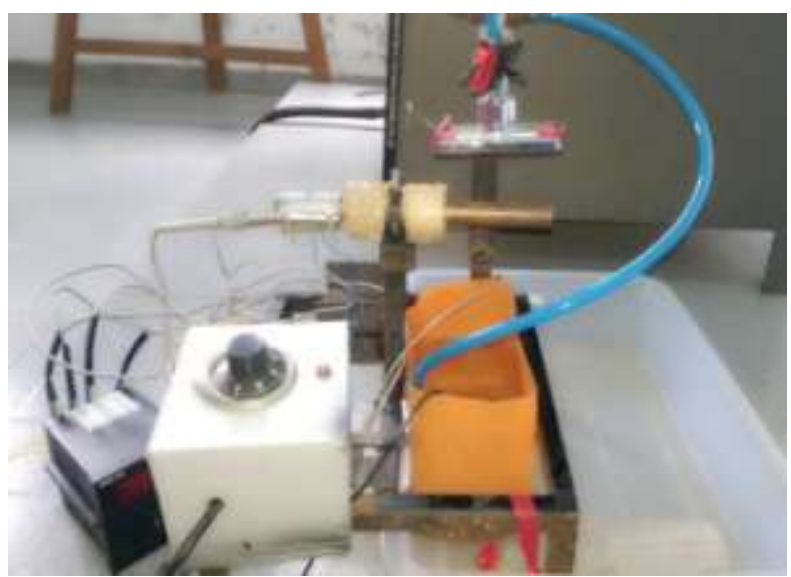

Fig-3.1: Actual Image of experimental setup

\subsection{Selection Heat Pipe}

One of the design parameter of heat pipe is selecting the operating temperature range [12]. In this project setting the operating temperature range as $20-70^{\circ} \mathrm{C}$, since there are many conventional application falling in this range. The boiling point of the acetone falls in the selected operating temperature. Selecting the working fluid as acetone, since useful range of acetone is $0-100^{\circ} \mathrm{C}$ [3]. The compatible material for acetone is Copper with high thermal conductivity [3]. Hence, the Copper is selected as pipe wall material. The ratio of length to diameter is between 6 to 28 , [3], [4], [17]. The larger the diameter more cross-sectional area available to allow the vapour to move from the evaporator to condenser. This allows the greater power carrying capacity [17]. Hence, selecting the outer diameter $20 \mathrm{~mm}$ and length $250 \mathrm{~mm}$, with $\mathrm{L} / \mathrm{D}=12.5$ as it will give a greater power carrying capacity and better understanding of fluid flow inside the heat pipe during simulation. The heat pipe is procured from market and the experiment was performed on it.

Specifications

1. Wall material : Copper

2. Working Fluid: Acetone

Dimensions

1. Diameter: $20 \mathrm{~mm}$

2. Total length: $250 \mathrm{~mm}$

3. Evaporator length: $60 \mathrm{~mm}$

4. Adiabatic length: $90 \mathrm{~mm}$

5. Condenser length: $100 \mathrm{~mm}$

6. Vapour core diameter: $13 \mathrm{~mm}$

7. Wick thickness: $2 \mathrm{~mm}$

8. Wall thickness: $1.5 \mathrm{~mm}$

Experimental setup consists of the heating strip of inside diameter $20 \mathrm{~mm}$ and length $60 \mathrm{~mm}$ for heating the evaporator section. The pump discharging the water through the shower at constant mass flow rate of $0.025 \mathrm{~kg} / \mathrm{s}$ is provided as a sink on the condenser section of heat pipe i.e. for $100 \mathrm{~mm}$ length. The adiabatic section of $90 \mathrm{~mm}$ is insulated using heatlon foam sheet to minimize the heat loss from this portion. The simple 8-channel digital temperature indicator with k-type thermocouples, temperature range of $0-600^{\circ} \mathrm{C}$ were used to measure the temperatures at adiabatic and condenser section, while the FLIR's thermal imaging camera is used for measuring the temperature at evaporator section.

\subsection{Procedure}

The experiment was performed for the two cases with sink and without sink. In with sink case, the evaporator section was heat upto $332 \mathrm{~K}$ and the wall temperature was measured along the length of wall. Similarly it was performed for without sink case.

\subsection{Results}

The heat transfer rate of heat pipe was calculated using, $\mathrm{Q}=\mathrm{m} . \mathrm{cp} . \Delta \mathrm{T} \ldots$ (1). Since we know that one of major characteristic of heat pipe is Effective Thermal conductivity 
$\left(\mathrm{K}_{\mathrm{eff}}\right)[2]$. Considering the heat pipe as solid, we can use Fourier's law of conduction, $\mathrm{Q}=\mathrm{K}_{\mathrm{eff}} \cdot \mathrm{A}$. ( $\left.\mathrm{dt} / \mathrm{dx}\right) \ldots(2)$ to calculate $\mathrm{K}_{\mathrm{eff}}$.

The heat transfer rate for with sink case is 225.3 watts and for without sink case is 176.7 watts. The wall temperature measured along the length of heat pipe for two cases are shown in graphs below:

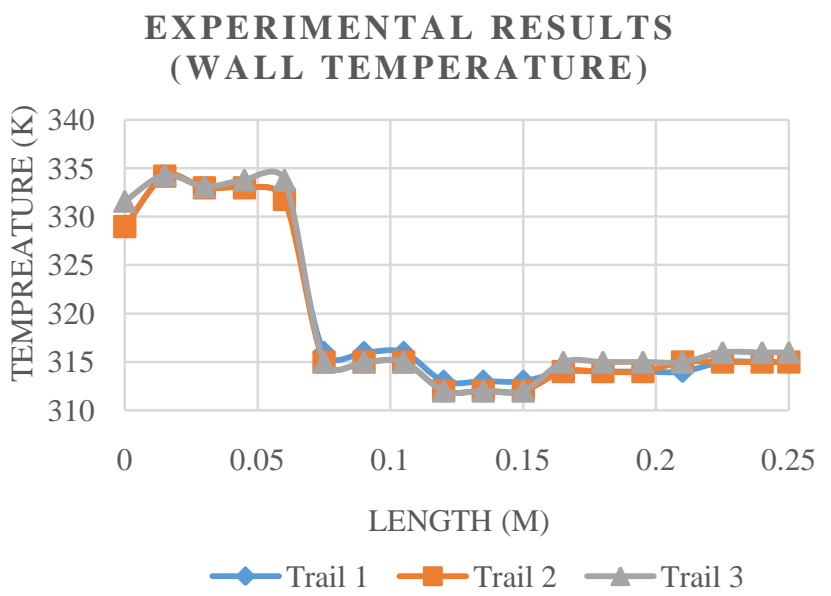

Fig-3.1: Wall temperature with sink

EXPERIMENTAL RESULTS

(WALL TEMPERATURE)

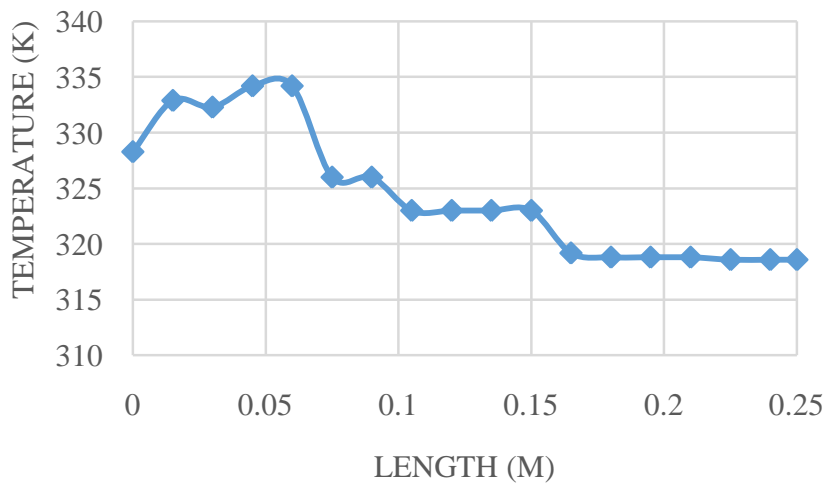

Fig-3.2: Wall temperature without sink

\section{CFD ANALYSIS OF HEAT PIPE}

In this section methodology used for CFD analysis is discussed.

\subsection{Geometry Description and Mesh Generation}

In CFD grid generation is an essential step. The accuracy of the CFD solution depends on the number of cells. The larger number of cell better the solution accuracy [12]. In this project GAMBIT is used for generating mesh.

Geometry of heat pipe and proposed heat pipe is made in GAMBIT, where the surface area of proposed heat pipe is increased by $18.4 \%$ by making it of diverging cross-section. The Meshed geometries of heat pipe and proposed heat are shown in figure below.

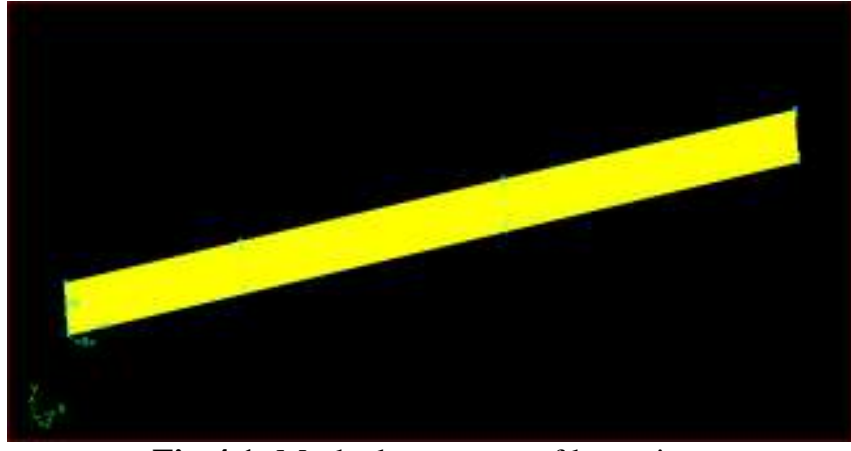

Fig-4.1: Meshed geometry of heat pipe

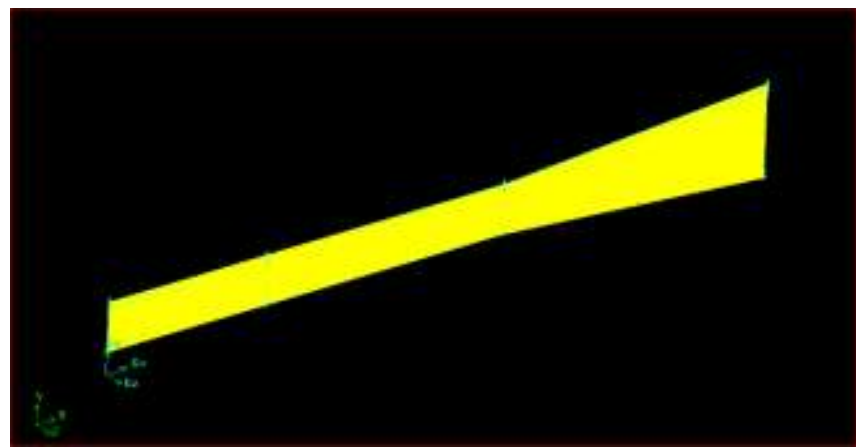

Fig-4.2:Meshed geometry of proposed heat pipe

The details of mesh for heat pipe and proposed heat pipe are given in table 1 and 2 respectively.

Table-1: Meshing of heat pipe

\begin{tabular}{|l|l|}
\hline & Heat Pipe \\
\hline Size of mesh & $\begin{array}{l}0.25 \text { for vapour zone } \\
0.1 \text { for liquid zone }\end{array}$ \\
\hline Number of cells & 230000 \\
\hline Number of nodes & 232593 \\
\hline Minimum Orthogonal Quality & 0.999965 \\
\hline Maximum Aspect Ratio & 2.69 \\
\hline
\end{tabular}

Table-2: Meshing of proposed heat pipe

\begin{tabular}{|l|l|}
\hline & Proposed Heat Pipe \\
\hline Size of mesh & $\begin{array}{l}0.25 \text { for vapour zone } \\
0.1 \text { for liquid zone }\end{array}$ \\
\hline Number of cells & 230276 \\
\hline Number of nodes & 232872 \\
\hline Minimum Orthogonal Quality & 0.996581 \\
\hline Maximum Aspect Ratio & 5.56 \\
\hline
\end{tabular}

\subsection{Solution Setup}

Since the heat pipe involves the phenomena of the evaporation and condensation a Mixture multiphase model was selected for CFD Analysis of heat pipe with the number of Eulerian phases as two. The Energy model was turned on which allows to set parameters related to energy or heat 
transfer. The viscous laminar model was selected for this purpose.

The working fluid in heat pipe is Acetone $\left(\mathrm{C}_{6} \mathrm{H}_{3} \mathrm{O}\right)$, therefore selecting the acetone liquid and acetone vapour because two phases are included in this problem. In a phases, the primary phase was set as acetone vapour, while the secondary phase as acetone liquid.

In the interaction section number of mass transfer mechanism was set as one. The mass transfer from phase-2 to phase-1 was selected, and the evaporation condensation mechanism was used.

In cell zone condition acetone liquid top and bottom was set as porous zone.

In boundary conditions, the type is selected as wall for evaporator, condenser and adiabatic wall. The boundary conditions are given the help of temperatures measured during experiment. Since multiphase model is used, the problem is simplified by using constant wall temperature boundary conditions at evaporator $=332 \mathrm{~K}$ and at condenser $=314.5 \mathrm{~K}$. For adiabatic section under the thermal tab heat flux was set as zero.

\subsection{Numerical Solution Approach}

The pressure based solver is used for analysis of heat pipe. The pressure-based solver employs an algorithm which belongs to a general class of methods called the projection method. In the projection method, wherein the constraint of mass conservation (continuity) of the velocity field is achieved by solving a pressure (or pressure correction) equation. The pressure equation is derived from the continuity and the momentum equations [16].

To obtain the solution more quickly the SIMPLEC scheme is used with a pressure under-relaxation factor set to 1 which speed-up the convergence. But in many cases by increasing an under-relaxation factor can lead to instability. For such a cases the value of under-relaxation factor is should be reduced to 0.7 or simply use the SIMPLE scheme. So for the simulation of heat pipe a SIMPLE Scheme was selected. The First order upwind scheme was selected to solve a pressure, momentum, volume fraction and energy. In a residual monitors an absolute residual criteria was set as 0.001 for continuity, x-velocity, y-velocity and vf-phase2; while for energy it was set as 0.000001 .

\subsection{Results}

The results obtained from the CFD are shown below in temperature contours and velocity vectors. XY plots of temperature vs. axial position are shown in next section 5 .

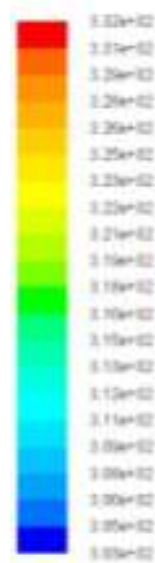

Fig-4.3: Temperatures contours (with sink)

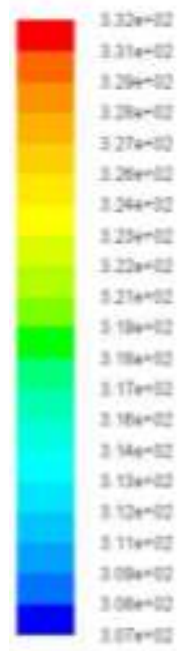

Fig-4.4: Temperature contours (Without sink)

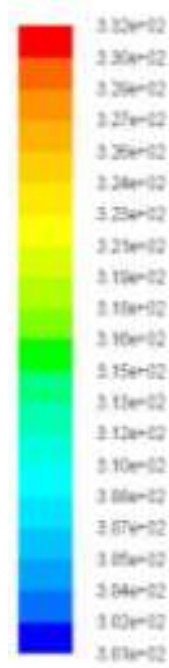

Fig-4.5: Temperature contours of proposed heat pipe (With sink) 


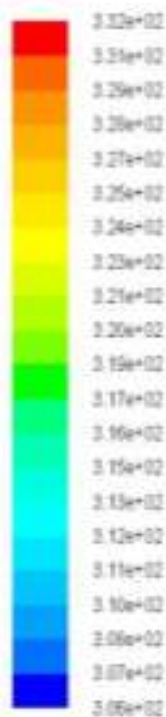

Fig-4.6: Temperature contours of proposed heat pipe (without sink)

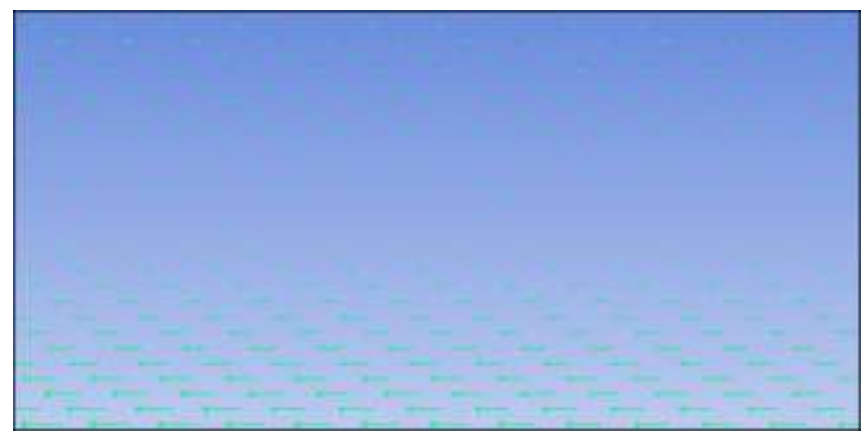

Fig-4.7: Velocity Vectors at condenser end of heat pipe

\section{VALIDATING RESULTS}

The wall temperatures obtained from the experiment and CFD are plotted in graphs using excel. The wall temperature along the length of heat pipe from experiment and CFD are superimposed and the net heat transfer is compared for each case and percent of error is shown.

\section{Case 1: With Sink}

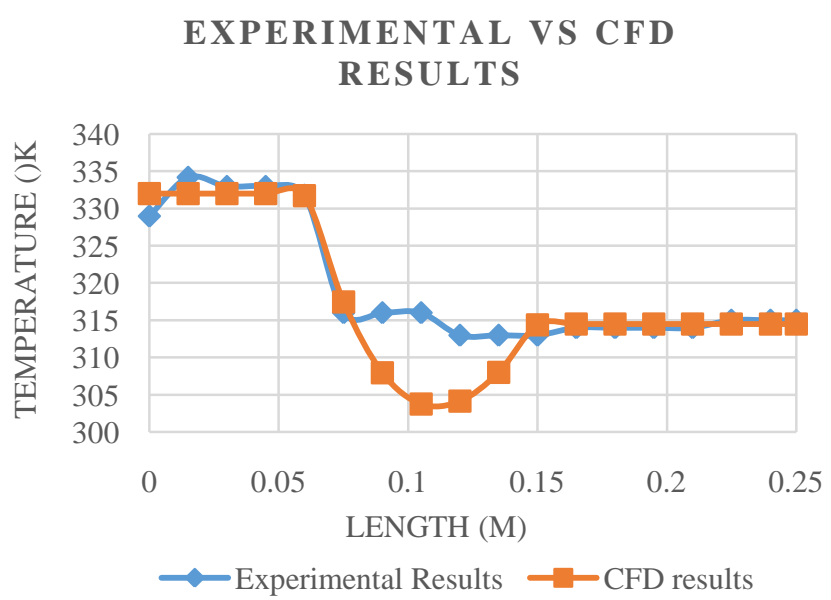

Fig-5.1: Experimental vs. CFD - With sink
The error range of the temperature profile for experiment and CFD results is $0-5.1 \%$ which is within acceptable range. Hence, we conclude that validation of CFD model for with sink case is done successfully.

The heat transfer rate for heat pipe with sink is 225.3 watts and 230.58 watts from experiment and CFD respectively.

Therefore, Maximum Error \%

$=\left[\left(\mathrm{Q}_{\mathrm{CFD}}-\mathrm{Q}_{\mathrm{E}} \mathrm{Xp}\right) / \mathrm{Q}_{\mathrm{Exp}}\right] * 100$

$=[(230.58-225.3) / 225.3] * 100$

$=2.34 \%$

The error for the heat transfer rate is $2.34 \%$ which is acceptable. Hence, it is said that CFD model for heat pipe is validated with an experiment on heat pipe.

\section{Case 2: Without Sink}

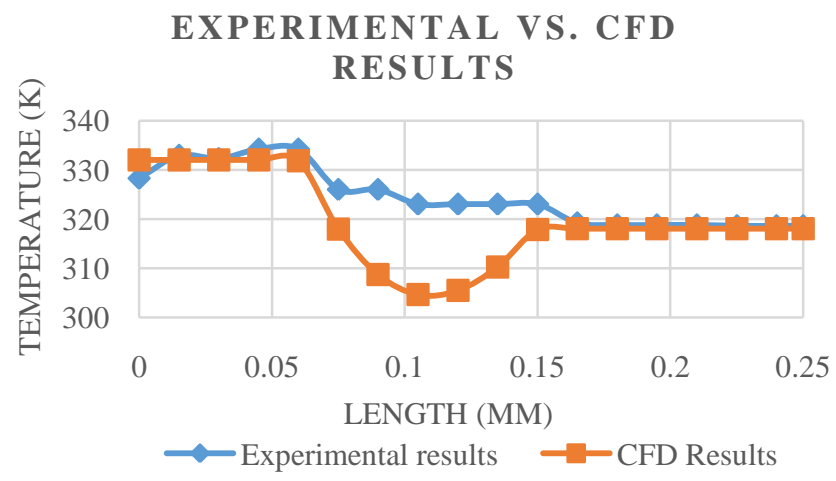

Fig-5.2: Experimental vs. CFD - Without sink

The above graph is evident that the wall temperature for experiment of heat pipe without sink and CFD model of heat pipe is in similar pattern and the range of error is between 0$7 \%$ which is very small. Hence, we conclude that the validation of CFD model for without sink case is performed successfully.

The heat transfer rate for heat pipe without sink is 176.7 watts and 198.82 watts from experiment and CFD respectively.

Therefore, Maximum Error \%

$=\left[\left(\mathrm{Q}_{\mathrm{CFD}}-\mathrm{Q}_{\mathrm{E}} \mathrm{Xp}\right) / \mathrm{Q}_{\mathrm{Exp}}\right]^{* 100}$

$=[(198.82-176.7) / 176.7] * 100$

$=12.5 \%$

Since, the validation of heat pipe was performed successfully we can say that the proposed model of heat pipe can also give desired results because the methodology used for modelling the proposed heat pipe is same.

\section{COMPARISON OF HEAT PIPE AND PROPOSED HEAT PIPE}

The comparison of results obtained from heat pipe and proposed heat pipe for the wall temperature and heat transfer are given below. 


\section{Case 1: With Sink}

\section{HEAT PIPE VS. PROPOSED HEAT PIPE}

(WALL TEMPERATURE)

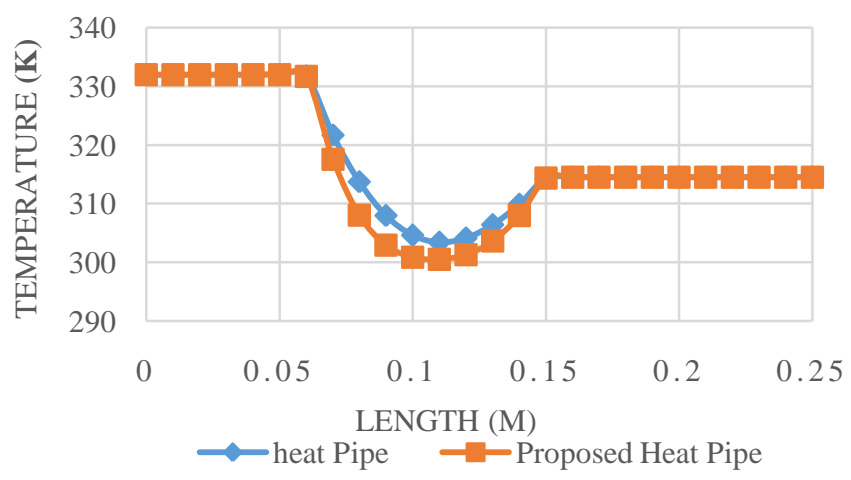

Fig-6.1: Heat pipe vs. Proposed heat pipe - With sink

The heat interaction predicted from CFD for with sink case Heat pipe $=230.58 \mathrm{~W}$

Proposed heat pipe $=334.75 \mathrm{~W}$

$\%$ Increase in heat transfer rate

$=\left[\left(\mathrm{Q}_{\text {proposed heat pipe }}-\mathrm{Q}_{\text {heat pipe }}\right) / \mathrm{Q}_{\text {heat pipe }}\right]^{* 100}$

$=[(334.75-230.58) / 230.58] * 100$

$=45.1 \%$

\section{Case 2: Without Sink}

\section{HEAT PIPE VS. PROPOSED HEAT PIPE}

(WALL TEMPERATURE)

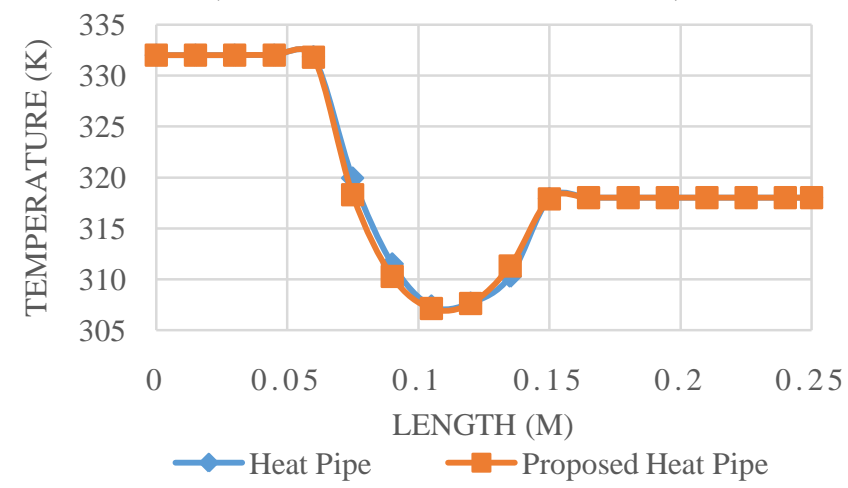

Fig-6.2: Heat pipe vs. Proposed heat pipe - Without sink

The heat interaction predicted from CFD for without sink case

Heat pipe $=198.81 \mathrm{~W}$

Proposed heat pipe $=237.5 \mathrm{~W}$

$\%$ Increase in heat transfer rate

$=\left[\left(\mathrm{Q}_{\text {proposed heat pipe }}-\mathrm{Q}_{\text {heat pipe }}\right) / \mathrm{Q}_{\text {heat pipe }}\right]^{* 100}$

$=[(237.5-198.81) / 198.81] * 100$

$=19.2 \%$

\section{CONCLUSION}

In this project the experiment on heat pipe were carried out to validate CFD model developed for heat pipe. The results obtained from the CFD are in good agreement with an experimental results. Hence, the validation is done successfully. It is also concluded that CFD model developed for proposed (or modified) heat pipe using same technique will also show good results.

By comparing the results obtained from CFD models developed for heat pipe and proposed heat pipe it is concluded that, the proposed model provided with sink gives around $45 \%$ of increase in heat transfer rate and proposed model without sink gives around $19 \%$ of increase in heat transfer rate. Hence, it is said that the enhancement in performance in terms of heat transfer is achieved by proposed (or modified) heat pipe. It is also concluded that heat pipe gives a better performance when heat sink is provided. The results of this project shows that CFD analysis of heat pipe can be successfully modelled using mixture multiphase model.

\section{REFERENCES}

[1] R.S. Gaugler (June 1944), "Heat pipe devices" United States Patent Office 2,350,348

[2] D.A. Reay, P.A. Kew and R.J. McGlen, "Heat pipes: Theory, Design and Applications"

[3] Amir Faghri, 2014, "Heat pipes: Review, Opportunities and Challenges", International journal of Frontiers of heat pipe (FHP), 5, 1 (2014)

[4] Patrik NEMEC, Josef HUZVAR, 2007, "Mathematical calculation of total heat power of the sodium heat pipe"

[5] Fabian Korn, 2008, "Heat pipes and its applications", Department of energy science, Lund University, Sweden

[6] Amir Faghri, 2012, "Review and advances in heat pipe science and technology", Journal of heat transfer, December, 2012, Vol. 134, DOI: 10.11 15/1.4007407

[7] Patrick McGinty, 2013, "Lighted helmet with pipe assembly", United States Patent No.: US 8,550,650 B1, Date of patent: Oct. 8, 2013

[8] N. Hariharan et al., 2014, "CFD Thermal Analysis on Laptop Cooling System using Loop Heat Pipe Technology", IJRET, eISSN: 2319-1163 pISSN: 23217308

[9] Asghar Alizadehdakhel et al., 2009, "CFD Modelling of flow and heat transfer in a thermosyphon" International Communications in Heat and Mass Transfer 37 (2010) 312-318

[10] Hussam Jouhara et al. 2009, "CFD Modelling of a Two-Phase Closed Thermosyphon Charged with R134a and R404a”, Umm Al-Qura University, Makkah 
[11] J.M. Tourier and M.S. EL-Genk, 1994, "A heat pipe transient analysis model", Int. J. Heat and Mass Transfer, Vol, 37, No. 5, pp. 753-762, 1994

[12] H K Versteeg and W Malalasekera, "An Introduction to Computational Fluid Dynamics - The finite volume method" (Second Edition)

[13] John D. Anderson, JR, “Computational Fluid Dynamics - The basics with applications"

[14] Fluent 6.3 User Guide (23.1.1)

[15] Fluent 6.3 User Guide (23.3.1, 23.4.1, 23.5.1)

[16] Fluent 6.3 User Guide (25.1.1 - Pressure based solver)

[17] Aavid Thermalloy- www.aavid.com 